\title{
Which out-of-office measurement technique should be used for diagnosing hypertension in prehypertensives?
}

\author{
Şükrü Ulusoy ${ }^{1} \cdot$ Gülsüm Özkan ${ }^{2} \cdot$ Mustafa ArıcI $^{3}$ • Ülver Derici ${ }^{4} \cdot$ T. Akpolat $^{5} \cdot$ Şule Şengül $^{6} \cdot$ Rahmi Yılmaz $^{3}$. \\ Şehsuvar Ertürk ${ }^{6}$ Yunus Erdem ${ }^{3}$ on behalf of the Turkish Society of Hypertension and Renal Diseases
}

Received: 9 July 2019 / Revised: 24 October 2019 / Accepted: 25 October 2019 / Published online: 7 November 2019

(c) The Author(s), under exclusive licence to Springer Nature Limited 2019. This article is published with open access

\begin{abstract}
Hypertension (HT) is diagnosed with high office blood pressure (BP), although confirmation with the addition of out-ofoffice measurements is currently recommended. However, insufficient data are available concerning the use of out-of-office BP measurement techniques for the diagnosis of HT in the prehypertensive population. The aim of the present study was to determine which out-of-office measurements yielded earlier and more frequent detection of development of HT in prehypertensive patients. Two hundred seven prehypertensive patients under monitoring in the Cappadocia cohort were included in the study. Office BP was measured five times at 1-min intervals, followed by 24-h ambulatory BP monitoring (24-h ABPM). Home BP measurement (HBPM) was performed five times, at the same times in the morning and evening, at 1 -min intervals for 1 week. The same procedure was carried out at $4-6$-month intervals for $\sim 2$ years. HT was diagnosed in $25.6 \%$ of subjects, masked HT in $11.1 \%$, and white coat HT in $2.9 \%$, while $23.7 \%$ remained prehypertensive and $36.7 \%$ became normotensive. Briefly, $56.6 \%$ of the patients with HT were diagnosed with office plus 24-h ABPM, $13.2 \%$ with office plus HBPM, and 30.2\% with office plus HBPM and 24-h ABPM. Office with 24-h ABPM yielded statistically significantly more diagnoses $(p<0.001)$. In conclusion, our prospective observational study evaluated the usefulness of outof-office BP measurements in confirming diagnosis of HT in prehypertensive patients. The findings show that 24-h ABPM detected HT earlier and more frequently in this high-risk population.
\end{abstract}

\section{Introduction}

Hypertension (HT) is a widespread global health problem, the prevalence of which is increasing, and one with high morbidity and mortality. The general prevalence of HT in the

Gülsüm Özkan

gulsumozkan78@hotmail.com

1 Department of Nephrology, School of Medicine, Karadeniz Technical University, Trabzon, Turkey

2 Department of Nephrology, School of Medicine, Namık Kemal University, Tekirdağ, Turkey

3 Department of Nephrology, School of Medicine, Hacettepe University, Ankara, Turkey

4 Department of Nephrology, School of Medicine, Gazi University, Ankara, Turkey

5 Department of Nephrology, Liv Hospital, Istinye University, Istanbul, Turkey

6 Department of Nephrology, School of Medicine, Ankara University, Ankara, Turkey
2018 European Society of Cardiology (ESC) and European Society of Hypertension (ESH) guideline is 30-45\% [1].

The diagnosis and treatment of HT depends on accurate blood pressure (BP) measurement. Reliable BP measurement is performed with intra-arterial $\mathrm{BP}$ measurement. However, since this method is effectively impossible in clinical practice, BP is measured using noninvasive methods. Office BP is the most commonly employed BP measurement technique [2]. The disadvantages of diagnosing HT solely in the office setting include measurement errors, the limited number of measurements that can be conveniently taken, and the confounding risk for isolated clinical HT [3, 4]. Almost all HT guidelines therefore state that diagnosis of HT should be confirmed with repeated office BP measurements, or out-of-office BP measurements (home BP monitoring (HBPM) or 24-h ambulatory BP monitoring (24-h ABPM)) [1, 5, 6]. Numerous studies have shown that 24-h ABPM is the gold standard in confirming diagnosis of HT, and that HBPM yields more reliable results than office BP measurement. The two out-of-office BP measurement methods have also been proved to be more 
reliable than office BP measurement in predicting cardiovascular events (CVEs) [7, 8].

Studies have compared HT diagnosis confirmation rates using consecutive office BP measurements, 24-h ABPM, or HBPM, in patients with high office BP. These have reported that office and HBPM are not as reliable as 24-h ABPM in diagnosing HT [9-11]. However, since 24-h ABPM is not available in all clinics and due to concerns over costs, the confirmation of diagnosis of HT in the event of high office BP using one of the out-of-office BP measurement methods appears now to be generally accepted $[1,5,6]$. In addition, there is no explicit information and advice concerning the use of out-of-office BP measurement in the screening and followup of HT in patients with optimal and prehypertensive BP values. The recently published 2018 ESH/ESC guideline recommends confirmation with out-of-office BP measurement due to potential suspicion of masked HT in individuals with elevated BP (SBP 130-139 mmHg, DBP 85-89 mmHg) [1].

$\mathrm{BP}$ values between optimal BP and stage $1 \mathrm{HT}$ have historically been classified using such terminology as "transient HT," "borderline HT," "high-normal BP," and "prehypertension." Irrespective of the range and terminology, the development of HT and cardiovascular morbidity and mortality are accepted as being more common in this patient group compared with the optimal BP group [12-14].

The aim of our prospective cohort study was to show which of 24-h ABPM and HBPM measurements in addition to office BP measurement revealed development of HT earlier and more frequently in patients diagnosed as prehypertensive with office BP and followed-up for $\sim 2$ years.

\section{Material and method}

\section{Cappadocia cohort}

This prospective cohort study is being conducted by the Turkish Society of Internal Medicine (TIHUD) [15]. The observational component commenced in March 2013. Following receipt of informed written consent, subjects' baseline data were collected using a 167-question electronic questionnaire. This produced information concerning demographic characteristics, lifestyle, and medical history, including diagnosed illnesses and medication use. All subjects underwent detailed physical examinations at which BP (at least twice), body weight, height, and waist circumferences were measured. BP measurement at time of enrollment in the cohort was performed in line with Joint National Committee 7 (JNC 7) guideline [16]. All participants are monitored annually in terms of changes in these parameters, onset of new illnesses, changes in weight or waist circumference, medication use, smoking status, alcohol consumption, and dietary characteristics.
Nonpharmacological measures had been proposed to prehypertensive patients due to ethical necessity.

\section{Patient selection}

Two years after the start of the cohort follow-up (January 2015), prehypertensive individuals identified based on two office measurements in 2013 from among 5150 individuals under monitoring in the Cappadocia cohort were randomly invited to participate in the study. Three hundred twentyseven individuals agreed to participate, and 207 meeting the inclusion criteria at the first office visit and fully completing the stages of the study protocol at the first visit were enrolled (Fig. 1). Individuals aged over 18, who had
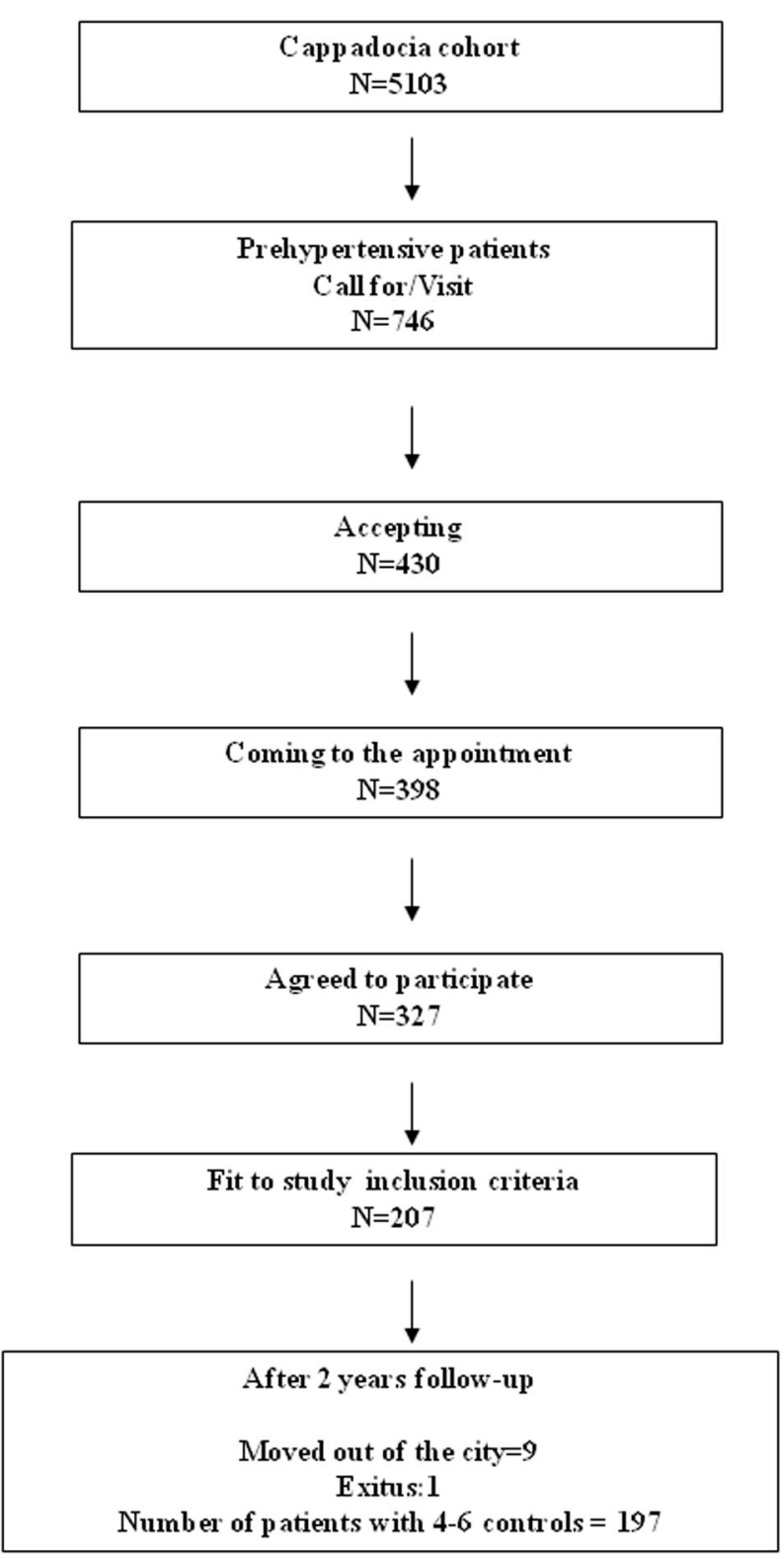

Fig. 1 Patient selection flow chart for the study 
been informed about the study and expressed verbal willingness to take part, and with sufficient intellectual capacity to provide a medical history, to measure $\mathrm{BP}$ at home and to perform 24-h ABPM, were enrolled. Pregnant women, and patients with known heart failure, kidney failure, or chronic liver disease, using antihypertensive drugs, or refusing to provide contact details were excluded. Ethical committee approval for the study was obtained from the Hacettepe University Medical Faculty, Turkey. The study commenced following receipt of informed written consent from subjects.

\section{Study protocol}

Selection of the 207 individuals agreeing to take part in the study, based on BP measurements performed during inclusion in the cohort 2 years previously, was carried out in line with the JNC 7 guideline. Patients with an office BP measurement $\geq 140 / 90 \mathrm{mmHg}$, and a 24-h ABPM all-day average $\geq 130 / 80 \mathrm{mmHg}$, and/or a home BP measurement $(\mathrm{HBPM}) \geq 135 / 85 \mathrm{mmHg}$ were diagnosed with HT. Patients with office BP values of 120-139/80-89 $\mathrm{mmHg}$ were regarded as prehypertensive. Patients who were normotensive at office BP measurement but in whom HT was identified at HBPM and/or 24-h ABPM were regarded as having masked HT, while those determined as hypertensive at office measurement but normotensive at HBPM and at 24-h ABPM were evaluated as having white coat HT (WCHT) [16].

Following recording of demographic data at the first office visit, the 207 subjects included in the study underwent detailed physical examinations. Height, weight, and waist circumference were measured. Office BP was measured in accordance with the JNC 7 guideline [16]. Oneweek HBPM was then performed, followed by 24-h ABPM. Office, home, and 24-h ABPM measurements were repeated once every 4-6 months during the follow-up process. Patients diagnosed with HT at any visit were monitored in line with the JNC 7 guideline [16]. Hypertensive patients were referred to family medicine practitioners for evaluation, treatment, and follow-up.

\section{Office BP measurement}

Office BP was measured using a UA-651SL monitor (A\&D Company, 1-243 Asahi, Kitamoto-shi, Saitama-ken.3648585 Japan), a validated device. Before the procedure, all patients were asked to rest for at least $5 \mathrm{~min}$ in a relaxed position in a quiet room at a comfortable temperature. We asked the patients whether they had consumed any caffeine, alcohol, or cigarettes in the previous $30-60 \mathrm{~min}$. BP was measured by a physician from both arms using a cuff of a suitable size for the patient's upper arm, with the upper arm held at heart level, with the back and the upper arm supported, and with the patient sitting upright. We were careful to ensure that patients did not cross their legs or speak during the procedure. Once BP had been measured from both arms, subsequent BP measurements were carried out using the arm eliciting the highest value. BP was measured five times at 1-min intervals. The first measurement was excluded from the analysis. The mean value of the next four measurements was recorded as office BP. Office BP measurement was repeated following the same procedure at each visit every 4-6 months.

\section{Home BP measurement}

An UA-651SL monitor (A\&D Company, 1-243 Asahi, Kitamoto-shi, Saitama-ken.364-8585 Japan) device was used for HBPM. Patients measured their own home BP after receiving the appropriate training. $\mathrm{BP}$ was measured five times at 1-min intervals every morning and evening for 1 week, in line with current guideline recommendations [1]. At the end of that period, mean morning and evening values were calculated and recorded as home BP values. HBPM was repeated following the same procedure at each visit every 4-6 months, and the devices used were randomized.

\section{Ambulatory BP measurement}

A Mobil-O-Graph NG 24 h ABPM Classic (I.E.M. GmbH, Stolberg, Germany) device was used to measure 24-h ABPM. Patients recorded times spent sleeping, waking, and eating, together with daily activities performed. Sleeping-waking periods were evaluated accordingly. Patients were also asked to ensure that the arm was kept immobile during BP measurement. Daytime BP measurement was performed at 15 -min intervals and night-time measurement at 30-min intervals. Subjects with at least 70\% measurement records for 24-h ABPM were included in the analysis [1]. Measurements were performed using the same procedure at each visit every 4-6 months, and the ABPM devices were randomized.

\section{End point}

Office BP measurement $\geq 140 / 90 \mathrm{mmHg}$ at any visit from the first, while HBPM was $\geq 135 / 85 \mathrm{mmHg}$ or mean daytime 24-h ABPM was $\geq 130 / 80 \mathrm{mmHg}$, was defined as HT. Patients with $\mathrm{HBPM}<135 / 85 \mathrm{mmHg}$ and mean daytime 24-h $\mathrm{ABPM}<130 / 80 \mathrm{mmHg}$ despite office BP measurements $\geq 140 / 90 \mathrm{mmHg}$ throughout the study were regarded as WCHT, and patients with office BP measurement $<140 / 90 \mathrm{mmHg}$ and $\mathrm{HBPM} \geq 135 / 85 \mathrm{mmHg}$ and/or mean daytime 24-h $\mathrm{ABPM} \geq 130 / 80 \mathrm{mmHg}$ were regarded as masked HT. 
Table 1 Baseline demographic parameters of whole study population and demographic data of normotensive, prehypertensive, and hypertensive patients at the end of the study

\begin{tabular}{|c|c|c|c|c|}
\hline & \multirow{2}{*}{$\begin{array}{l}\text { Baseline } \\
\text { Whole population } \\
(n=207) \text { Mean } \pm \text { SD }\end{array}$} & \multicolumn{3}{|l|}{ At the end of the study } \\
\hline & & $\begin{array}{l}\text { Normotensive }(n=76) \\
\text { Mean } \pm \text { SD }\end{array}$ & $\begin{array}{l}\text { Prehypertensive }(n=49) \\
\text { Mean } \pm \text { SD }\end{array}$ & $\begin{array}{l}\text { Hypertensive }(n=53) \\
\text { Mean } \pm \text { SD }\end{array}$ \\
\hline BMI $\left(\mathrm{kg} / \mathrm{m}^{2}\right)$ & $29.94 \pm 4.96$ & $28.39 \pm 4.8$ & $30.88 \pm 5.03$ & $31 \pm 4.51$ \\
\hline Office SBP (mmHg) & $122.60 \pm 14.24$ & $109.97 \pm 4.55$ & $125.01 \pm 6.37$ & $142.5 \pm 10.33$ \\
\hline Office DBP (mmHg) & $78.25 \pm 9.14$ & $70.25 \pm 4.78$ & $79.29 \pm 6.13$ & $90.98 \pm 7.82$ \\
\hline Home SBP (mmHg) & $116.33 \pm 11.69$ & $109.29 \pm 5.88$ & $117.05 \pm 8.85$ & $130.22 \pm 10.84$ \\
\hline Home DBP (mmHg) & $72.63 \pm 7.32$ & $69.18 \pm 4.07$ & $71.96 \pm 6.05$ & $79.11 \pm 7.05$ \\
\hline $\begin{array}{l}\text { 24-h-ABPM all-day } \\
\text { SBP }(\mathrm{mmHg})\end{array}$ & $120.16 \pm 11.90$ & $106.61 \pm 9.13$ & $112.07 \pm 15.48$ & $122.9 \pm 22.83$ \\
\hline $\begin{array}{l}\text { 24-h-ABPM all-day } \\
\text { DBP }(\mathrm{mmHg})\end{array}$ & $75.48 \pm 8.36$ & $67.24 \pm 5.53$ & $73.66 \pm 6.96$ & $89.82 \pm 12.53$ \\
\hline
\end{tabular}

$B M I$ body mass index, 24- $h A B P M$ 24-h ambulatory blood pressure monitoring, $S B P$ systolic blood pressure, $D B P$ diastolic blood pressure

\section{Statistical analysis}

PASW 18.0 for Windows software was employed for statistical analysis. Descriptive statistics were expressed as number and percentage for categorical variables and as mean, standard deviation, and median (minimum-maximum) for numerical variables. Since normal distribution conditions were not established for the numerical variables of age and BMI, the Mann-Whitney U test was used in the comparison of groups with HT, prehypertension, and normotension over 24 months, while the chi-square test was used to compare the categorical variable of gender. $p$ values lower than 0.05 were regarded as statistically significant.

\section{Results}

The Cappadocia cohort study involving 5150 individuals commenced in 2013, and 327 subjects with prehypertension identified with office BP measurement at the start of the cohort agreed to participate in the present study. Two hundred seven prehypertensive subjects capable of measuring BP with office BP, HBPM, and 24-h ABPM were finally included.

The median age of the 207 subjects in the study was 50 years, and $62.3 \%$ were women. Two years previously in the initial cohort, the average office BP of the same 207 individuals was $127.76 \pm 6.53 / 76.04 \pm 7.59 \mathrm{mmHg}$. Baseline demographic parameters of the entire study population and demographic data of normotensive, prehypertensive, and hypertensive patients at the end of the study are shown in Table 1. A median number of five [4-6] visits were performed over a mean follow-up period of $23.30 \pm 1.75$ months, with an average time between visits of $4.31 \pm 1.26$ months. After the first control, nonpharmacological measures were proposed to prehypertensive patients for ethical reasons.
Table 2 Distribution of HT classification of patients and the method by which they are determined

\begin{tabular}{llc}
\hline & Method & $N: 207(\%)$ \\
\hline HT & Office with 24-h-ABPM $(n=30)$ & $53(25.60 \%)$ \\
& $\begin{array}{l}\text { Office with HBPM }(n=7) \\
\text { Office with 24-h ABPM and }\end{array}$ \\
& HBPM $(n=16)$ & \\
Masked HT & 24-h ABPM $(n=19)$ & $23(11.1 \%)$ \\
& HBPM $(n=1)$ & \\
White coat HT & HBPM with 24-h ABPM $(n=3)$ & $6(2.9 \%)$ \\
Prehypertension & & $49(23.7 \%)$ \\
Normotension & & $76(36.7 \%)$ \\
\hline
\end{tabular}

$H T$ hypertension, 24- $h$ ABPM 24-h ambulatory blood pressure monitoring, $H B P M$ home blood pressure monitoring

At the end of 2 years, HT was determined in $25.6 \%$ of subjects, while $23.7 \%$ remained prehypertensive and $36.7 \%$ became normotensive. The BP measurement methods by which patients were diagnosed with HT and distribution by HT classifications at the end of the study are presented in Table 2. As shown in Table 2, WCHT was observed at a rate of $2.9 \%$ and masked $\mathrm{HT}$ at $11.1 \%$.

Thirty $(56.6 \%)$ of the 53 patients diagnosed with HT were diagnosed with office and 24-h ABPM, seven (13.2\%) with office and HBPM, and 16 (30.2\%) with office plus HBPM and 24-h ABPM (Table 2). Statistically significantly more diagnoses were made with office plus 24-h ABPM $(p<0.001)$. HT was detected in 29 patients at the first control, 12 patients at the second, six patients at the third, four patients at the fourth, and two patients at the sixth. At initial controls, $62.1 \%$ of the 29 patients were diagnosed HT with office BP plus 24-h ABPM, and 58.3\% of the 12 patients were diagnosed at the second control. Diagnosis rates were significantly higher with this method 


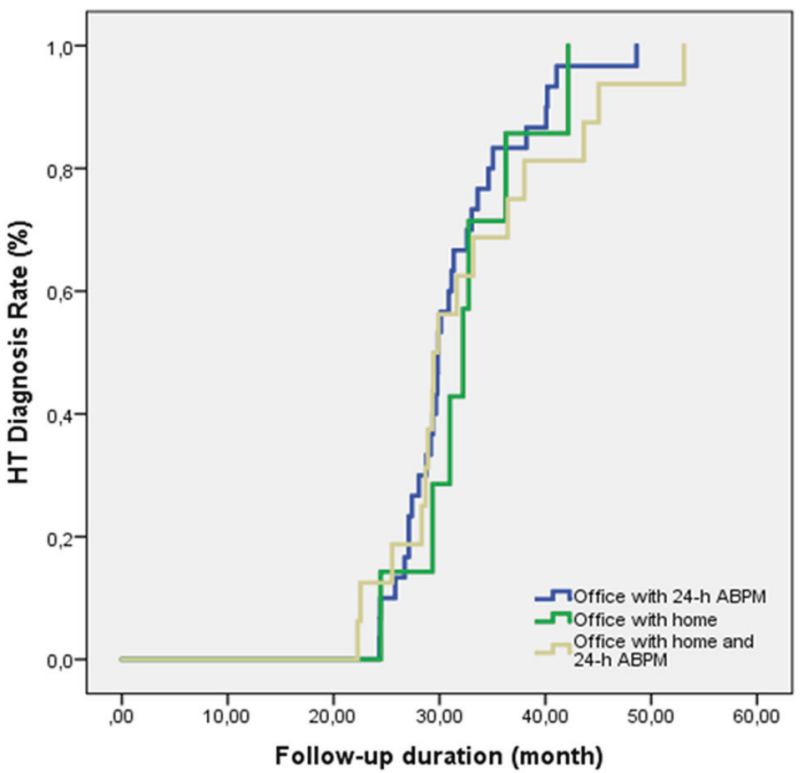

Fig. 2 HT detection times and rates of the methods used

than with office plus HBPM or office plus HBPM and 24-h $\operatorname{ABPM}(p=0.001)$ (Fig. 2).

\section{Discussion}

In this prospective, observational, cohort study, we examined and followed-up 207 subjects diagnosed as prehypertensive. We used automated devices for measuring BP under both home and office conditions and also for 24-h ABPM. At the end of the follow-up, HT was diagnosed in $25.6 \%$ of subjects, masked HT in $11.1 \%$, and WCHT in $2.9 \%$, while $23.7 \%$ remained prehypertensive and $36.7 \%$ became normotensive. HT was diagnosed more frequently and earlier with office plus 24-h ABPM than office plus HBPM or office plus HBPM and 24-h ABPM. Some of the prehypertensive individuals may have become normotensive after complying with recommendations regarding lifestyle changes made for ethical reasons at each control.

The prevalence of HT, irrespective of age, is $\sim 32 \%$, while the Turkish Society of Hypertension and Renal Diseases cites a figure of $30.3 \%$ in Turkey $[1,5,6,16,17]$. A mean 4-year HT incidence rate of $21.4 \%$ was determined in the HinT study [18]. Although ours was not an incidence study, we determined HT in $25.6 \%$ of subjects in the 4-year period from the beginning of the cohort study and our 2-year prospective follow-up. The greater incidence of HT in our research than in the 4-year HinT study may be due to our study involving a prehypertensive patient group. Several previous studies have shown that prehypertensives frequently develop HT. Selassie at al. monitored 18,865 nonhypertensive individuals for 7 years and determined development of HT in $63.8 \%$. Presence of prehypertension emerged as a significant predictor of development of HT [19]. In the TRial Of Preventing HYpertension study, HT developed in $40.4 \%$ of prehypertensive patients monitored with lifestyle modification in the second year and in $63 \%$ at the end of 4 years [14]. Studies have also shown that in addition to HT development, CVEs are also more common in prehypertensive individuals $[12,13]$.

The difficulty with HT is not limited to its high prevalence. Another major problem is that various controversial issues regarding the diagnosis of HT have still not been resolved. One particular problem involves BP measurement being correctly performed for diagnosis of HT. Unfortunately, levels of BP measurement and of correct measurement are both quite low worldwide [3, 4]. Office BP measurement is the oldest method of diagnosing HT, but for reasons such as low levels of correct BP measurement, and the inability to determine conditions such as WCHT and masked HT using office $\mathrm{BP}$, the use of out-of-office methods is recommended in order to confirm diagnosis $[1,2,5]$. While the majority of HT guidelines recommend the use of out-of-office BP measurement methods, particularly under some specific conditions, the NICE guideline was the first to emphasize the role of 24-h ABPM in confirming diagnosis of HT [6]. In later years, other HT guidelines also began recommending the use of out-ofoffice BP measurement methods in confirming diagnosis of HT $[1,5]$. Previous studies and the majority of guidelines recommend the use of out-of-office BP measurements in individuals with high BP. However, there are no explicit recommendations concerning the use of out-of-office BP measurements in the screening and follow-up of HT in the prehypertensive population, with its high risk of HT development. However, due to the high incidence of masked HT in individuals with high-normal BP, the 2018 ESH/ESC guideline recommended out-of-office BP measurement in these individuals [1]. The purpose of our study was to investigate the place of out-of-office BP measurements in the early diagnosis of HT in the monitoring of a prehypertensive population. Insufficient data are available on this subject in the literature. Our study showed that more patients were diagnosed with the out-of-office BP measurement methods 24-h ABPM and HBPM in a prehypertensive population with high rates of HT development and CVEs. The low number of patients diagnosed with HT made it difficult to compare the times of diagnosis between different methods. However, considering the number of patients diagnosed with HT with office BP plus 24-h ABPM, especially in the first two controls, we concluded that HT can be diagnosed earlier with office plus 24-h ABPM. In addition, 24-h ABPM was more effective than HBPM in detecting masked HT and WCHT.

The reported prevalence of WCHT in several previous studies is $\sim 13-35 \%$ [20-23]. Studies investigating cardiovascular-related and all-cause mortality and WCHT 
have determined a minimal increase in mortality in patients with WCHT $[24,25]$. The incidence of WCHT in our study was $2.9 \%$. This figure being lower than those in other studies may be due to the higher number of office BP measurements in our study [20-23]. The majority of studies determining the prevalence of WCHT have been performed using the average of two consecutive office BP measurements, while in our study five measurements were performed at 1-min intervals at every visit, with the first measurement being discarded and the average of the remaining values being recorded.

The reported prevalence of masked HT in population studies is $10-26 \%[21,26,27]$. The rate in our study was $11.1 \%$, which is compatible with the previous literature. In contrast to WCHT, there are studies showing that masked HT causes an increased cardiovascular risk as high as that in sustained HT [24, 26, 28]. We determined a not inconsiderable rate of masked HT with 24-h ABPM. We conclude that 24-h ABPM is more effective in this population with a high risk of developing HT and of CVEs.

There are a number of limitations to our prospective observational cohort study. One is that only office BP measurement was performed at the beginning of the cohort. However, one strength of our study is that we continued to perform all three measurements 4-6 times over the last 2 years. The patient number of 207 in the cohort initiated among a wide population derives from our selection of a prehypertensive population and in particular to the low number of patients willing to have 24-h ABPM performed 4-6 times. The low number of patients diagnosed with HT prevented us from performing various analyses and reduced the significance of some findings that might otherwise have been more significant.

In conclusion, this prospective observational cohort study demonstrates the role of out-of-office BP measurements in confirming diagnosis of HT in the prehypertensive group, a subject on which sufficient data are lacking. Our findings show that more HT was detected with 24-h ABPM in the screening and follow-up of HT in this high-risk population. In addition, we observed that ABPM is more useful than home measurement in the diagnosis of masked HT, another important problem. We think that other studies performed in the light of our research will further strengthen the place of 24-h ABPM in the diagnosis of HT in the prehypertensive group.

\section{Summary table}

\section{What is known about topic}

- The diagnosis and treatment of HT depends on accurate BP measurement.
- Office BP is the most commonly employed BP measurement technique.

- The disadvantages of diagnosing HT solely in the office setting include measurement errors, the limited number of measurements that can be conveniently taken, and the confounding risk for isolated clinic HT.

- Almost all HT guidelines therefore state that diagnosis of HT with repeated office BP measurements, or out-ofoffice BP measurements (HBPM or 24-h ABPM) should be confirmed.

- In addition, there is no explicit information and advice concerning the use of out-of-office BP measurement in the screening and follow-up of HT in patients with optimal and prehypertensive BP values.

\section{What this study adds}

- Our prospective observational study evaluated the usefulness of out-of-office BP measurements in confirming diagnosis of HT in prehypertensive patients.

- We showed that 24-h ABPM detected HT earlier and more frequently in this high-risk population.

Acknowledgements This study was supported by the Turkish Society of Hypertension and Renal Diseases.

\section{Compliance with ethical standards}

Conflict of interest The authors declare that they have no conflict of interest.

Publisher's note Springer Nature remains neutral with regard to jurisdictional claims in published maps and institutional affiliations.

Open Access This article is licensed under a Creative Commons Attribution 4.0 International License, which permits use, sharing, adaptation, distribution and reproduction in any medium or format, as long as you give appropriate credit to the original author(s) and the source, provide a link to the Creative Commons license, and indicate if changes were made. The images or other third party material in this article are included in the article's Creative Commons license, unless indicated otherwise in a credit line to the material. If material is not included in the article's Creative Commons license and your intended use is not permitted by statutory regulation or exceeds the permitted use, you will need to obtain permission directly from the copyright holder. To view a copy of this license, visit http://creativecommons. org/licenses/by/4.0/.

\section{References}

1. Williams B, Mancia G, Spiering W, Agabiti Rosei E, Azizi M, Burnier M, et al. Authors/Task Force Members: 2018 ESC/ESH guidelines for the management of arterial hypertension: the task force for the management of arterial hypertension of the European 
Society of Cardiology and the European Society of Hypertension: the task force for the management of arterial hypertension of the European Society of Cardiology and the European Society of Hypertension. J Hypertens. 2018;36:1953-2041.

2. Muntner P, Shimbo D, Carey RM, Charleston JB, Gaillard T, Misra S, et al. Measurement of blood pressure in humans: a scientific statement from the American Heart Association. Hypertension. 2019;73:e35-e66.

3. Ulusoy S,, Özkan G, Güvercin B, Sökmen Y, Erdem Y. Do physicians measure patients' blood pressure, and are those measurements reliable? J Hum Hypertens. 2018;32:203-11.

4. Sebo $P$, Pechère-Bertschi A, Herrmann FR, Haller DM, Bovier P. Blood pressure measurements are unreliable to diagnose hypertension in primary care. J Hypertens. 2014;32:509-17.

5. Whelton PK, Carey RM, Aronow WS, Casey DE Jr, Collins KJ, Dennison Himmelfarb C, et al. 2017 ACC/AHA/AAPA/ABC/ ACPM/AGS/APhA/ASH/ASPC/NMA/PCNA guideline for the prevention, detection, evaluation, and management of high blood pressure in adults: executive summary: a report of the American College of Cardiology/American Heart Association Task Force on clinical practice guidelines. Hypertension. 2018;71:1269-324.

6. National Institute for Health and Clinical Excellence. Hypertension (CG127). http://www.nice.org.uk/guidance/cg127. Accessed 30 Jan 2014.

7. Siu AL. U.S. Preventive Services Task Force. Screening for high blood pressure in adults: U.S. Preventive Services Task Force recommendation statement. Ann Intern Med. 2015;163:778-86.

8. Piper MA, Evans CV, Burda BU, Margolis KL, O'Connor E, Whitlock EP. Diagnostic and predictive accuracy of blood pressure screening methods with consideration of rescreening intervals: a systematic review for the U.S. Preventive Services Task Force. Ann Intern Med. 2015;162:192-204.

9. Larkin KT, Schauss SL, Elnicki DM. Isolated clinic hypertension and normotension: false positives and false negatives in the assessment of hypertension. Blood Press Monit. 1998;3:247-54.

10. Stergiou GS, Skeva II, Baibas NM, Kalkana CB, Roussias LG, Mountokalakis TD. Diagnosis of hypertension using home or ambulatory blood pressure monitoring: comparison with the conventional strategy based on repeated clinic blood pressure measurements. J Hypertens. 2000;18:1745-51.

11. Hodgkinson J, Mant J, Martin U, Guo B, Hobbs FD, Deeks JJ, et al. Relative effectiveness of clinic and home blood pressure monitoring compared with ambulatory blood pressure monitoring in diagnosis of hypertension: systematic review. Brit Med J. 2011;342:d3621.

12. Vasan RS, Larson MG, Leip EP, Kannel WB, Levy D. Assessment of frequency of progression to hypertension in non-hypertensive participants in the Framingham Heart Study: a cohort study. Lancet. 2001;358:1682-6.

13. Leitschuh M, Cupples LA, Kannel W, Gagnon D, Chobanian A. High-normal blood pressure progression to hypertension in the Framingham Heart Study. Hypertension 1991;17:22-7.

14. Julius S, Nesbitt SD, Egan BM, Weber MA, Michelson EL, Kaciroti N, et al. Trial of preventing hypertension (TROPHY) study investigators. Feasibility of treating prehypertension with an angiotensin-receptor blocker. N Engl J Med. 2006;354:1685-97.
15. Unal S, Ascioglu S, Demirkazik A, Ertenli I, Eskioglu E, Guler K, et al. Baseline data of a prospective cohort study: Cappadocia cohort study, Turkey. Turk J Public Health. 2018;16:190-203.

16. Chobanian AV, Bakris GL, Black HR, Cushman WC, Green LA, Izzo JL Jr, et al. The National High Blood Pressure Education Program Coordinating Committee. Seventh report of the Joint National Committee on Prevention, Detection, Evaluation, and Treatment of High Blood Pressure. Hypertension. 2003;42:1206-52.

17. Sengul S, Akpolat T, Erdem Y, Derici U, Arici M, Sindel S, et al. Turkish Society of Hypertension and Renal Diseases. Changes in hypertension prevalence, awareness, treatment, and control rates in Turkey from 2003 to 2012. J Hypertens. 2016;34:1208-17

18. Arici M, Turgan C, Altun B, Sindel S, Erbay B, Derici U, et al. Turkish Society of Hypertension and Renal Diseases. Hypertension incidence in Turkey (HinT): a population-based study. J Hypertens. 2010;28:240-4.

19. Selassie A, Wagner CS, Laken ML, Ferguson ML, Ferdinand KC, Egan BM, et al. Progression is accelerated from prehypertension to hypertension in blacks. Hypertension. 2011;58:579-87.

20. Martin CA, McGrath BP. White-coat hypertension. Clin Exp Pharm Physiol. 2014;41:22-9.

21. Tocci G, Presta V, Figliuzzi I, Attalla El Halabieh N, Battistoni A, Coluccia R, et al. Prevalence and clinical outcomes of white-coat and masked hypertension: analysis of a large ambulatory blood pressure database. J Clin Hypertens. 2018;20:297-305.

22. Pickering TG, James GD, Boddie C, Harshfield GA, Blank S, Laragh $\mathrm{JH}$, et al. How common is white coat hypertension? JAMA. 1988;259:225-8.

23. Piper MA, Evans CV, Burda BU, Margolis KL, O'Connor E, Whitlock EP, et al. Diagnostic and predictive accuracy of blood pressure screening methods with consideration of rescreening intervals: a systematic review for the U.S. Preventive Services Task Force. Ann Intern Med. 2015;162:192-204.

24. Fagard RH, Cornelissen VA. Incidence of cardiovascular events in white-coat, masked and sustained hypertension versus true normotension: a meta-analysis. J Hypertens. 2007;25:2193-8.

25. Pierdomenico SD, Cuccurullo F. Prognostic value of white-coat and masked hypertension diagnosed by ambulatory monitoring in initially untreated subjects: an updated meta analysis. Am J Hypertens. 2011;24:52-8.

26. Asayama K, Thijs L, Li Y, Gu YM, Hara A, Liu YP, et al. International Database on Ambulatory Blood Pressure in Relation to Cardiovascular Outcomes (IDACO) Investigators. Setting thresholds to varying blood pressure monitoring intervals differentially affects risk estimates associated with whitecoat and masked hypertension in the population. Hypertension. 2014;64:935-42.

27. Gorostidi M, Vinyoles E, Banegas JR, de la Sierra A. Prevalence of white-coat and masked hypertension in national and international registries. Hypertens Res. 2015;38:1-7.

28. Ohkubo T, Kikuya M, Metoki H, Asayama K, Obara T, Hashimoto J, et al. Prognosis of "masked" hypertension and "white-coat" hypertension detected by 24-h ambulatory blood pressure monitoring 10-year follow-up from the Ohasama study. J Am Coll Cardiol. 2005;46:508-15. 